\title{
Secretion of inhibin A and inhibin B throughout pregnancy and the early postpartum period in chimpanzees
}

\author{
M Kondo ${ }^{1,2}, \mathrm{~T}$ Udono ${ }^{3}$, W Z Jin ${ }^{2,4}, M$ Funakoshi ${ }^{4}, K_{\text {Shimizu }}{ }^{5}$, \\ M Itoh ${ }^{5}$, C B Herath ${ }^{4}$, G Watanabe ${ }^{2,4}$, N P Groome ${ }^{6}$ and \\ $\mathrm{KTaya}^{2,4}$ \\ ${ }^{1}$ Novartis Animal Health, Tokyo 105-6134, Japan \\ ${ }^{2}$ Department of Basic Veterinary Sciences, The United Graduate School of Veterinary Sciences, Gifu University, Gifu 501-1193, Japan \\ ${ }^{3}$ Kumamoto Primates Research Park, Sanwa Kagaku Kenkyusho Co., Ltd, Kumamoto 869-3201, Japan \\ ${ }^{4}$ Laboratory of Veterinary Physiology, Tokyo University of Agriculture and Technology, Tokyo 183-8509, Japan \\ ${ }^{5}$ Primate Research Institute, Kyoto University, Aichi 484-8506, Japan \\ ${ }^{6}$ School of Biological and Molecular Sciences, Oxford Brookes University, Oxford OX3 OBP, UK \\ (Requests for offprints should be addressed to K Taya, Laboratory of Veterinary Physiology, Faculty of Agriculture, Tokyo University of Agriculture and \\ Technology, 3-5-8, Saiwai-cho, Fuchu-shi, Tokyo, 183-8509 Japan; Email: taya@cctuat.ac.jp)
}

\begin{abstract}
Plasma concentrations of inhibin A and inhibin B during pregnancy and early lactation in chimpanzees were determined by enzyme-linked immunosorbent assay (ELISA). Plasma samples were taken from five pregnant chimpanzees at 6-9, 10, 20 and 25 weeks of pregnancy, and following parturition. Throughout pregnancy and the early postpartum period, circulating inhibin A and inhibin B concentrations remained low, at similar levels to those during the normal menstrual cycle in chimpanzees. Concentrations of inhibin A in the placental homogenate were high enough to be measured by the ELISA and by bioassay, whereas circulating inhibin bioactivities in late pregnancy were too low to be measured. Plasma concentrations of FSH remained low with no significant changes throughout pregnancy and the postpartum period. Plasma
\end{abstract}

concentrations of oestradiol-17 $\beta$ and progesterone at 25 weeks of pregnancy were much higher than normal menstrual cycle levels. It was concluded that in chimpanzees the levels of circulating inhibin $\mathrm{A}$ and inhibin $\mathrm{B}$ remained low throughout pregnancy and the early postpartum period, and that the concentrations of bioactive dimeric inhibin did not increase towards the end of pregnancy. The suppression of circulating FSH levels during pregnancy is suggested to be controlled by steroid hormones that increased significantly in late pregnancy, and the present findings further suggest that the secretory pattern and role of inhibin during pregnancy in chimpanzees may be different from that in human and other primates.

Journal of Endocrinology (2001) 168, 257-262

\section{Introduction}

Inhibin is a heterodimeric glycoprotein consisting of an alpha subunit and a beta subunit and was originally characterised as suppressing follicle-stimulating hormone (FSH) secretion. In women, inhibin is secreted from granulosa cells of follicles, by corpora lutea and by the placenta (de Jong 1988, McLachlan et al. 1988). There are many reports on inhibin secretion and production during pregnancy in humans (de Kretser 1995, Qu \& Thomas 1995, Petraglia 1997, Lockwood et al. 1998). These studies found that concentrations of inhibin in the peripheral circulation during pregnancy were very high compared with those during the normal menstrual cycle. In nonhuman primates, the profiles of immunoreactive (ir)inhibin throughout pregnancy and the postpartum period have also been studied using radioimmunoassay (RIA)
(Nozaki et al. 1990, Webley et al. 1991, Billiar et al. 1999), while the in situ hybridization technique has been used for detecting mRNAs of inhibin subunits (Schwall et al. 1990).

The chimpanzee provides a suitable model for understanding human reproductive endocrinology. Although the need to use non-human primates for the prediction of human reproductive parameters is increasing, some primates are not suitable because they have different reproductive endocrinological mechanisms from those seen in humans (Hobson et al. 1976).

In pregnant chimpanzees we have previously attempted to measure peripheral concentrations of ir-inhibin by RIA, but the concentrations were not in the detectable range. Furthermore, the bioactivity of peripheral inhibin during late pregnancy was also not detectable by inhibin bioassay using a pituitary cell culture system. A new specific ELISA 
for inhibin A and inhibin B has been developed to measure the different inhibin isoforms in humans (Groome et al. 1994, 1996) and the results have demonstrated the role of inhibins during human pregnancy (Petraglia et al. 1997). In order to determine the profiles of circulating inhibin A and inhibin $\mathrm{B}$ and to investigate how FSH is regulated in pregnant chimpanzees, we measured plasma concentrations of dimeric forms of inhibin throughout pregnancy and the early postpartum period. We also measured inhibin in placental homogenates. In addition, plasma concentrations of FSH, luteinizing hormone $(\mathrm{LH})$, progesterone and oestradiol- $17 \beta$ were determined using RIA.

\section{Materials and Methods}

\section{Animals}

Five pregnant female chimpanzees were used in the present study. Blood samples were collected at 6-9, 10, 20 and 25 weeks of pregnancy and at 3-5 weeks post partum; blood was drawn from the cubital vein under general anaesthesia induced by dropelidol (Sankyo Ltd, Tokyo, Japan) and ketamine (Sankyo Ltd). The experimental protocol was approved in accordance with the 'Guidelines for the Care and Use of Laboratory Primates', prepared by Kyoto University. The blood samples for ELISA were collected in heparinised tubes and immediately centrifuged at $2000 \mathrm{~g}$ for $10 \mathrm{~min}$ at $4{ }^{\circ} \mathrm{C}$ and stored at $-20{ }^{\circ} \mathrm{C}$. Pooled serum collected from late pregnant chimpanzees was used for bioassay. Following delivery, the placenta was homogenised with normal saline $(1 \mathrm{~g}$ placenta/ml) using a homogeniser (Hiscotoron, Nichion Ltd, Tokyo, Japan) and centrifuged at $25000 \mathrm{~g}$ for $30 \mathrm{~min}$ at $4{ }^{\circ} \mathrm{C}$. The supernatant was used for inhibin determination by bioassay and ELISA.

Hormone assays for inhibin $A$, inhibin $B, F S H, L H$, oestradiol-17 $\beta$ and progesterone

Plasma concentrations of inhibin A and inhibin B and diluted placental homogenates $(0 \cdot 25,0 \cdot 5$, and $1 \mathrm{~g} / \mathrm{ml})$ were measured using a commercially available ELISA kit (Serotec Ltd, Oxford, Oxon, UK) developed for human inhibin A and inhibin B (Groome et al. 1994, 1996). The standard used for the inhibin A and inhibin B assay was a partially immunopurified inhibin standard from human follicular fluid, calibrated against recombinant $32 \mathrm{kDa}$ human inhibin A or inhibin B (Genentech, San Francisco, CA, USA) and the results were expressed in terms of this recombinant form.

Concentrations of plasma FSH were measured by double-antibody RIA using NIDDK-human (h) FSH-I-4 as antigen, NIDDK-anti-hFSH-6 as the first antiserum and LER907 as the standard.

Concentrations of plasma LH were measured by double-antibody RIA using NIDDK-hLH-I-3 as antigen,
NIDDK-anti-hLH-2 as the first antiserum and LER 907 as the standard. Peripheral plasma of early pregnant chimpanzees contained large amounts of chimpanzee chorionic gonadotrophin (cCG), which produced displacement curves parallel to those of the human standard in the LH RIA system. Thus, LH levels are referred to as $\mathrm{LH} / \mathrm{cCG}$ equivalents, since the LH antiserum cross-reacts with cCG. The intra- and interassay coefficients of variation were, respectively, $8.8 \%$ and $9 \cdot 3 \%$ for $\mathrm{LH}$ and $6 \cdot 3 \%$ and $6.5 \%$ for $\mathrm{FSH}$.

Plasma concentrations of oestradiol-17 $\beta$ and progesterone were determined by a double-antibody RIA system using ${ }^{125}$ I-labelled radioligands as described previously (Taya et al. 1985). Antisera against oestradiol-17 $\beta$ (GDN\#244) (Korenman et al. 1974) and progesterone (GDN\#377) (Gibori et al. 1977) were kindly provided by Dr G D Niswender (Animal Reproduction and Biotechnology, Colorado State University, Fort Collins, CO, USA). The intra- and interassay coefficients of variation were, respectively, $5 \cdot 8 \%$ and $11 \cdot 4 \%$ for oestradiol- $17 \beta$, and $3.5 \%$ and $13.4 \%$ for progesterone.

\section{Bioassay of inhibin}

Bioactivity of inhibin was determined using an assay for suppression of FSH release from cultured cells of rat anterior pituitary, as reported previously (Taya \& Sasamoto 1987). A partially purified bovine follicular fluid (bFF) inhibin preparation obtained after immunoaffinity chromatography was used as a reference standard for bioassay (Miyamoto et al. 1987). The placental homogenate at four dilutions $(0 \cdot 016-1 \mathrm{~g} / \mathrm{ml})$ and a peripheral blood sample taken at late pregnancy at three dilutions $(13-50 \mu \mathrm{l})$ were used to check parallelism with the standard.

\section{Statistical analysis}

Independent variables predictive of inhibin A and inhibin $B$ were identified with linear multiple regression analysis. A two-sided $P$ value less than 0.05 was considered significant. All data were expressed as means \pm s.E.M. When a significant effect was obtained with one-way ANOVA, Student's $t$-test or Cochran-cox test was used to analyse the significance of the difference between two means. A value of $P<0.05$ was considered to be statistically significant. In the assays, dilutions of plasma, serum and placental homogenate were used to check for parallelism with the standards by $2 \times 2$ point analysis.

\section{Results}

Characterization of ELISA for inhibin $A$ and inhibin $B$ assays

Serial dilutions of placental extracts and plasma were compared with the standard curve for inhibin A (Fig. 1A) and inhibin B (Fig. 1B). All curves obtained from the 


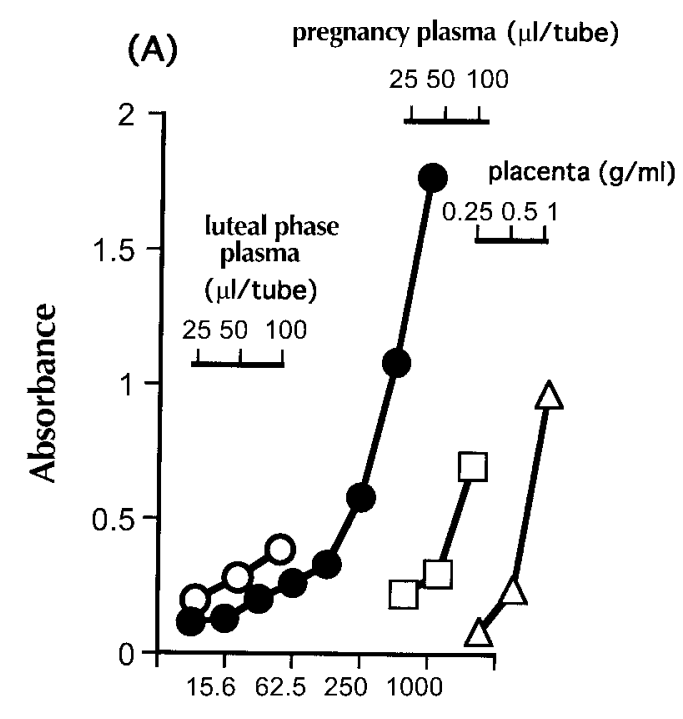

Inhibin A (pg/ml)

(B)

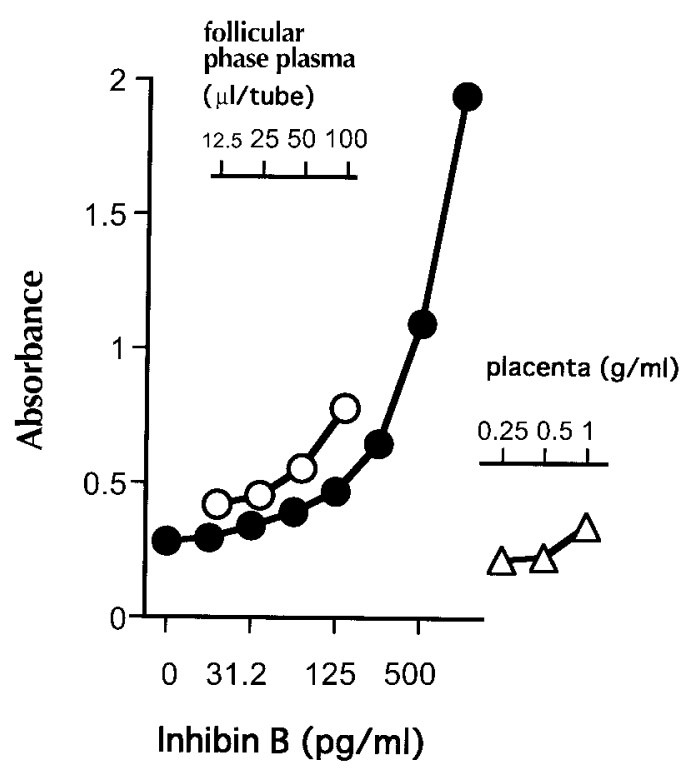

Figure 1 Two-site ELISA dose-response curves of (A) human inhibin $A(\mathbf{O})$ and $(B)$ human inhibin $B(0)$ in plasma samples of a pregnant chimpanzee $(\square)$, homogenate of placenta $(\triangle)$ and pooled plasma in the normal menstrual cycle $(\bigcirc)$. Each value represents the mean of duplicate determinations.

serially diluted samples were parallel to the standard curve within the possible range of sample volume (up to $100 \mu \mathrm{l} /$ tube for peripheral blood and $1 \mathrm{~g} / \mathrm{ml}$ for homogenate), indicating that using the present ELISA system it was possible to measure the concentrations of inhibin A and inhibin $\mathrm{B}$ in peripheral plasma and placental homogenate of the chimpanzee.
Plasma concentrations of inhibin $A$, inhibin $B, F S H, L H$, oestradiol-17 $\beta$ and progesterone throughout pregnancy and in the early postpartum period

Plasma concentrations of inhibin A during the luteal phase tend to be higher than those during the follicular phase in the normal menstrual cycle (Fig. 2A). No significant differences in plasma concentrations of inhibin A were observed between different age levels of pregnancy. Postpartum plasma concentrations of inhibin A were significantly $(P<0 \cdot 05)$ lower than those at $6-9$ and 25 weeks of pregnancy.

Plasma concentrations of inhibin B during the follicular phase were significantly $(P<0 \cdot 05)$ higher than those found in the luteal phase of the normal menstrual cycle in chimpanzees (Fig. 2B). Plasma concentrations of inhibin B were very low, with only small changes throughout pregnancy and the early postpartum period, compared with those during the follicular and luteal phases of the normal menstrual cycle.

Plasma concentrations of FSH throughout pregnancy and the postpartum period were unchanged and the concentrations were significantly $(P<0 \cdot 05)$ lower than those of the follicular phase of the normal menstrual cycle in chimpanzees (Fig. 2C).

Plasma concentrations of $\mathrm{LH} / \mathrm{cCG}$ during the first half of pregnancy in chimpanzees were significantly $(P<0 \cdot 01)$ higher than those during the second half of pregnancy (Fig. 2D).

Plasma concentrations of oestradiol-17 $\beta$ (Fig. 2E), and progesterone (Fig. 2F) were significantly $(P<0.05)$ increased at 25 weeks of pregnancy compared with the early period of pregnancy and were significantly $(P<0 \cdot 05)$ decreased at postpartum. Both circulating oestradiol- $17 \beta$ and progesterone levels were much higher than in the normal menstrual cycle.

\section{Bioassay and ELISA of inhibin in placental homogenates}

Serial dilutions of chimpanzee placental homogenates suppressed FSH release from cultured rat anterior pituitary cells (Fig. 3B) and this dose-dependent response curve was parallel to the standard curve produced with bovine inhibin standard (Fig. 3A); the addition of different volumes of serum from late pregnant chimpanzees did not show parallelism (Fig. 3C). In the two-site ELISA, the dose-response curve produced by three diluted placental homogenates showed parallelism to the inhibin A standard but not to the inhibin B standard due to low concentrations of inhibin B.

\section{Discussion}

Chimpanzees have been recognised as suitable animal models for humans due to the similarities in reproductive 
physiology (Hobson et al. 1976). However, there have been only a few reports demonstrating the profiles of gonadotrophins and steroid hormones during pregnancy in

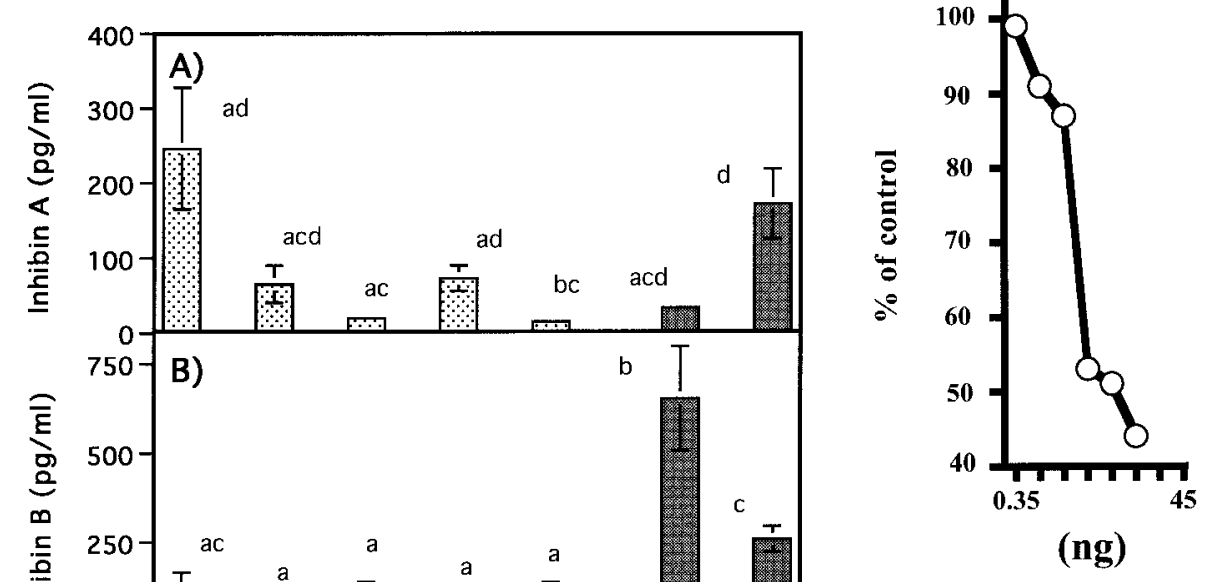

Figure 3 Dose-response curves of (A) bovine inhibin standard, (B) homogenate of chimpanzee placenta and (C) chimpanzee serum from late pregnancy in the inhibin bioassay. Each value represents the mean of triplicate determinations.

chimpanzees (Reyes et al. 1975, Hobson et al. 1976). The regulation of circulating $\mathrm{FSH}$ by inhibin and steroid hormones during pregnancy has not been documented.

The present study demonstrated that plasma inhibin A and inhibin $\mathrm{B}$ in female chimpanzees were measurable by the two-site ELISA method developed for the measurement of dimeric inhibin in humans (Groome et al. 1994, 1996). The present study shows that concentrations of circulating inhibin A and inhibin B remain at low levels throughout pregnancy until the early postpartum period in chimpanzees. In humans, it has been reported that circulating inhibin $\mathrm{A}$ is the dominant form of dimeric inhibin present during pregnancy and that the levels are elevated in the third trimester of pregnancy, reaching concentrations about 50 times higher than in the first and second trimesters of pregnancy; the concentrations of inhibin A decrease after term (Muttukrishna et al. 1995, Fowler et al. 1998). By contrast, no increase of dimeric inhibins was observed in late pregnancy in chimpanzees in the present study. From the viewpoint of comparative endocrinology, it is of interest to understand this different profile between humans and chimpanzees.

Figure 2 Changes in plasma concentrations of $(A)$ inhibin $A$, (B) inhibin $\mathrm{B}$, (C) FSH, (D) LH/CCG, (E) oestradiol-17 $\beta$, and (F) progesterone throughout pregnancy and the early postpartum period (Post), and during the follicular (Fo) and luteal (Lu) phases of the normal menstrual cycle in chimpanzees. Each value represents the mean \pm S.E.M. Different letters in each graph indicate a significant difference $(P<0.05)$ among groups (Student's $t$-test or Cochran-cox test). 
In addition, it was demonstrated that inhibin $\mathrm{A}$ in placental homogenates was detectable by the ELISA, but that inhibin $\mathrm{B}$ was not measurable in placental homogenates. Using human explant tissue culture, it has been reported that inhibins $\mathrm{A}$ and $\mathrm{B}$ are secreted by the chorion laeve, whereas only inhibin $\mathrm{A}$ is secreted by the placenta. Furthermore, only low concentrations of both dimeric inhibins are secreted by the decidua parietalis and amnion (Riley et al. 1996, 2000, Keelan et al. 1999) and the mRNA for the subunits of inhibin A has been detected in human placenta (Petraglia et al. 1987). It has been concluded that the placenta is a major source of circulating inhibin A in humans. It appears that although the chimpanzee placenta makes inhibin this does not cause a large rise in circulating inhibin $\mathrm{A}$ as is found in the human in late pregnancy.

Bioactivity of inhibin was detected in placental homogenates with a large amount of sample volume $(0.016-1 \mathrm{~g} / \mathrm{ml})$ while bioactivity of serum inhibin in late pregnancy was below the detection limit in chimpanzees. This is consistent with the ELISA result showing absence of a major rise in inhibin $A$ in the circulation. In the Japanese monkey we reported that the bioactivity of serum inhibin at pregnancy was detectable by the same bioassay (Nozaki et al. 1990). In humans, it was reported that the bioactivity of serum inhibin increased significantly in late pregnancy (Qu et al. 1991). In the present study it was clearly demonstrated that, compared with other species, the bioactivity of circulating inhibin was very low in late pregnancy in chimpanzees. This low level of bioactive inhibin in late pregnancy in chimpanzees was confirmed using ELISA which showed no significant increase of circulating dimeric inhibins during that period.

In humans, it has been reported that inhibin B can also be detected in the plasma of pregnant women despite its low concentrations - concentrations were more than five times higher in the third trimester than in early pregnancy (Petraglia et al. 1997). In other reports, it has been shown that inhibin B levels were detected in tissues such as the chorion laeve, decidua parietalis and amnion, but that circulating inhibin B levels were not significantly high (Riley et al. 2000). Caution has to be exercised in interpreting low concentrations of inhibin $\mathrm{B}$ in the presence of high concentrations of inhibin $\mathrm{A}$ because the inhibin B ELISA has a $0.5 \%$ cross-reaction with inhibin A (Wallace et al. 2000).

On the other hand, circulating progesterone and oestradiol- $17 \beta$ concentrations were increased in late pregnancy in chimpanzees and this confirms earlier findings that these steroids are secreted in large amounts by the placenta (Reyes et al. 1975, Hobson et al. 1976). Knight et al. (1998) reported that in sheep concentrations of plasma inhibin A remained low, whereas high concentrations of circulating progesterone and oestradiol-17 $\beta$ secreted from the placenta suppressed FSH levels in the late pregnant period. Therefore, based on these reports and the present study it is suggested that circulating progesterone and oestradiol-17 $\beta$, but not circulating inhibin appear to be important factors for maintaining lower FSH concentrations in late pregnancy in chimpanzees.

In early pregnancy in humans it was reported that the source of inhibin A is likely to be the fetal placenta and not the corpus luteum (Illingworth et al. 1996, Riley et al. 1996, Birdsall et al. 1997, Muttukrishna et al. 1997, Wallace et al. 1997). In contrast, the corpus luteum expresses inhibin during the luteal phase of the cycle in primates (Fraser et al. 1993). In the present study, the concentrations of inhibin A showed a tendency to be higher in early pregnancy and in the luteal phase than during other periods of pregnancy. Further study is required to investigate the source of inhibin $\mathrm{A}$ in early pregnancy in chimpanzees.

It is concluded that in chimpanzees the levels of circulating inhibin $\mathrm{A}$ and inhibin $\mathrm{B}$ remained low throughout pregnancy and the early postpartum period, and that the concentrations of bioactive dimeric inhibins did not increase towards the end of pregnancy, demonstrating that the chimpanzee's placenta, unlike other primates, does not produce a large amount of inhibins. In addition, the suppression of circulating FSH levels during pregnancy was suggested to be controlled by steroid hormones that increased significantly in late pregnancy, and the present findings further suggest that the secretory pattern and role of inhibin during pregnancy in chimpanzees may be different from that in humans and other primates.

\section{Acknowledgements}

We are grateful to the National Institute of Diabetes and Digestive and Kidney Diseases (NIDDK) and to Dr G D Niswender for their generous gifts.

\section{References}

Billiar RB, Leavitt MG, Smith P, Albrecht ED \& Pepe GJ 1999 Functional capacity of fetal zone cells of the baboon fetal adrenal gland: a major source of $\alpha$-inhibin. Biology of Reproduction $\mathbf{6 1}$ 142-146.

Birdsall M, Ledger W, Groome N, Abdalla H \& Muttukrishna S 1997 Inhibin A and activin A in the first trimester of human pregnancy. Journal of Clinical Endocrinology and Metabolism 82 1557-1560.

Fowler PA, Evans LW, Groome NP, Templeton A \& Knight PG 1998 A longitudinal study of maternal serum inhibin-A, inhibin-B, activin- $\mathrm{A}$, activin $\mathrm{AB}$, pro- $\alpha \mathrm{C}$ and follistatin during pregnancy. Human Reproduction 13 3530-3536.

Fraser HM, Lunn SF, Cowen GM \& Saunders PTK 1993 Localization of inhibin/activin subunit mRNAs during the luteal phase in the primate ovary. Journal of Molecular Endocrinology 10 245-257.

Gibori G, Anrczak E \& Rothchild I 1977 The role of estrogen in regulation of luteal progesterone secretion in the rat after day 12 of pregnancy. Endocrinology 100 1483-1495.

Groome NP, Illingworth PJ, O'Brien M, Cooke I, Ganesan TS, Baird DT \& McNeilly AS 1994 Detection of dimeric inhibin throughout 
the human menstrual cycle by two-site enzyme immunoassay. Clinical Endocrinology 40 717-723.

Groome NP, Illingworth PJ, O'Brien M, Pai R, Rodger FE, Mother MP \& McNeilly AS 1996 Measurement of dimeric inhibin B throughout the human menstrual cycle. Journal of Clinical Endocrinology and Metabolism 81 1401-1405.

Hobson W, Coulston F, Faiman C, Winter JSD \& Reyes F 1976 Reproductive endocrinology of female chimpanzees: a suitable model of humans. Journal of Toxicology and Environmental Health $\mathbf{1}$ 657-668.

Illingworth PJ, Groome NP, Duncan WC, Grant V, Tovanabutra S, Baird T \& McNeilly AS 1996 Measurement of circulating inhibin forms during the establishment of pregnancy. Journal of Clinical Endocrinology and Metabolism 81 1471-1475.

de Jong FH 1988 Inhibin. Physiological Reviews 68 555-607.

Keelan JA, Marvin KW, Sato TA, McCowan LM, Coleman M, Evans LW, Groome NP \& Mitchell MD 1999 Concentrations of activin A, inhibin A and follistatin in human amnion, choriodecidual and placental tissues at term and preterm. Journal of Endocrinology 163 99-106.

Knight PG, Feist SA, Tannetta DS, Bleach ECL, Fowler PA, O'Brien M \& Groome NP 1998 Measurement of inhibin-A ( $\alpha \beta A$ dimer) during the oestrous cycle, after manipulation of ovarian activity and during pregnancy in ewes. Journal of Reproduction and Fertility 113 159-166.

Korenman SG, Steven RH, Carpenter LA, Robb M, Niswender GD \& Sherman BM 1974 Oestradiol radioimmunoassay without chromatography: procedure, validation and normal value. Journal of Clinical Endocrinology and Metabolism 38 718-720.

de Kretser DM 1995 Inhibin in pregnancy. Clinical Endocrinology 42 389.

Lockwood GM, Muttukrishna S \& Ledger WL 1998 Inhibins and activins in human ovulation, conception and pregnancy. Human Reproduction Update 4 284-295.

McLachlan RL, Robertson DM, de Kretser DM \& Burger HG 1988 Advances in the physiology of inhibin and inhibin related peptides. Clinical Endocrinology 29 77-112.

Miyamoto K, Hasegawa Y, Fukuda M, Igarashi M, Kangawa K \& Matsuno H 1987 Isolation and characterization of porcine and bovine follicular fluid inhibins. In Inhibin-Non-Steroidal Regulation of Follicle Stimulating Hormone Secretion, pp 47-59. Eds HG Burger, DM de Krester, JK Findlay \& M Igarashi. New York: Raven Press.

Muttukrishna S, George L, Fowler PA, Groome NP \& Knight PG 1995 Measurement of serum concentrations of inhibin-A ( $\alpha-\beta A$ dimer) during human pregnancy. Clinical Endocrinology 42 391-397.

Muttukrishna S, Child TJ, Groome NP \& Ledger WL 1997 Source of circulating levels of inhibin A, pro alpha C-containing inhibins and activin A in early pregnancy. Human Reproduction 12 1089-1093.

Nozaki M, Watanabe G, Taya K, Katakai Y, Wada I, Sasamoto S \& Oshima K 1990 Changes in circulating inhibin levels during pregnancy and early lactation in the Japanese monkey. Biology of Reproduction 43 444-449.

Petraglia F 1997 Inhibin, activin and follistatin in the human placenta - a new family of regulatory proteins. Placenta 18 3-8.
Petraglia F, Sawchenko P, Lim AT, Rivier J \& Vale W 1987 Localization, secretion, and action of inhibin in human placenta. Science 10 187-189.

Petraglia F, Luisi S, Benedetto C, Zonca M, Florio P, Casarosa E, Volpe A, Bernasconi S \& Genazzani AR 1997 Changes of dimeric inhibin B levels in maternal serum throughout healthy gestation and in women with gestational diseases. Journal of Clinical Endocrinology and Metabolism 82 2991-2995.

Qu J \& Thomas K 1995 Inhibin and activin production in human placenta. Endocrine Reviews 16 485-507.

Qu J, Vankrieken L, Brulet C \& Thomas K 1991 Circulating bioactive inhibin levels during human pregnancy. Journal of Clinical Endocrinology and Metabolism 72 862-866.

Reyes FI, Winter JSD, Faiman C \& Hobson WC 1975 Serial serum levels of gonadotropins, prolactin and sex steroids in the nonpregnant and pregnant chimpanzee. Endocrinology 96 $1447-1455$.

Riley SC, Wathen NC, Chard T, Groome NP \& Wallace EM 1996 Inhibin in extra-embryonic coelomic and amniotic fluids and maternal serum in early pregnancy. Human Reproduction $\mathbf{1 1}$ 2772-2776.

Riley SC, Leask R, Balfour C, Brennand JE \& Groome NP 2000 Production of inhibin forms by the fetal membranes, decidua, placenta and fetus at parturition. Human Reproduction 15 578-583.

Schwall RH, Mason J, Wilcox JN, Bassett SG \& Zeleznik AJ 1990 Localization of inhibin/activin subunit mRNAs within the primate ovary. Molecular Endocrinology 4 75-79.

Taya K \& Sasamoto S 1987 Selective release of FSH in lactating rats during the period of follicular atresia induced by the administration of antiserum to LH-releasing hormone. Journal of Endocrinology 118 455-464.

Taya K, Watanabe G \& Sasamoto S 1985 Radioimmunoassay for progesterone, testosterone and oestradiol-17 $\beta$ using 125-Iiodohistamine radioligands. Japanese Journal of Animal Reproduction 31 186-197.

Wallace EM, Riley SC, Crossley JA, Ritoe SC, Horne A, Shade M, Ellis PM, Aitken DA \& Groome NP 1997 Dimeric inhibin in amniotic fluid, maternal serum, and fetal serum in human pregnancy. Journal of Clinical Endocrinology and Metabolism 82 218-222.

Wallace EM, Schneider-Kolsky M \& Thirunavukarasu P 2000 Activin A, inhibin A, inhibin B and parturition: changes of maternal and cord serum levels according to the mode of delivery. British Journal of Obstetrics and Gynaecology 107 704-705.

Webley GE, Knight PG, Given A \& Hodges JK 1991 Increased concentrations of immunoreactive inhibin during conception cycles in the marmoset monkey: suppression with an LHRH antagonist and cloprostenol. Journal of Endocrinology 128 465-473.

Received in final form 1 September 2000
Accepted 18 October 2000 